\title{
FORMAÇÃO DO PROFISSIONAL DE SAÚDE \\ ESTRUTURA OCUPACIONAL E DEMANDAS EDUCACIONAIS
}

João Carlos Pedrazzani *

ReBEn/09

PEDRAZZANI, J.C. - Formação do profissional de saúde. Estrutura ocupacional e demandas educacionais. Rev. Bras. Enf.; DF, 33 : 477-482, 1980.

A formação e a utilização de recursos humanos para a saúde no Brasil estiveram, basicamente, sempre determinadas pelo mercado de trabalho no setor. Em outras palavras, têm sido as modalidades, a extensão e as caracte-rísticas dos serviços que determinam a produção de recursos humanos e sua utilização, com graus variados de desajustes.

Não importa que as instituições formadoras não tenham articulação formal com as instituições utilizadoras. Como umas e outras são resultados de um mesmo processo gerador e respon. dem aos mesmos determinantes estruturais, as primeiras tendem sempre a se ajustar às características da demanda ou exigência de trabalhos dominantes nas segundas.

No âmbito dos serviços, é conhecida a natureza elitista dominante nas práticas de saúde no país. Os serviços de saúde atendem principalmente às ne- cessidades dos grupos sociais de maior poder, concentrando-se nas áreas urbanas e com tendências marcantes à sofisticação.

O conteúdo de tais serviços apóiase em uma certa mistificação do conhecimento médico, cujo domínio e aplisação estão, social e juridicamente, assegurados como monopólios de determinadas categorias profissionais. Tal monopólio provê mecanismos para promover a expansão desejada das necessidades de assistência médica pela medicalização crescente da sociedade.

Por outro lado, evidencia-se a baixa eficácia dos serviços de saúde no Brasil, quando se comparam os indicadores de produção desses serviços com os de saúde de nossa população. Para uma produção aproximada de 170 milhões de consultas médicas por ano, ostentamos indicadores de mortalidade já em muito superados por países com níveis de desenvolvimento e disponibilidade de re-

* Auxiliar de Ensino do Departamento de Ciências da Saúde da Universidade Federal de São Carlos. 
PEDRAZZANI, J.C. - Formação do profissional de saúde. Estrutura ocupacional e demandas educacionais. Rev. Bras. Enf.; DF, $33: 477-482,1980$.

cursos inferiores aos nossos e a prevalência extendida de enfermidades facilmente evitáveis. (Macedo, 1977, pág. 19).

A própria condição de sobrevivência de nossa população é um dos fatores que demonstram a ineficiência dos serviços de saúde. Em São Paulo, entre 1960 a 1965, houve aumento real do salário-mínimo do país ao que correspondeu o declínio da mortalidade infantil, enquanto que o achatamento salarial entre 1965 e 1970 provocou aumento dos índices de mortalidade infantil. (Leser, 1972).

Nos debates sobre os problemas nacionais de saúde e possíveis soluções, omite-se freqüentemente o fato de que a concentração de recursos médicos na área urbana ocorre quando $40 \%$ de nossa população continuam a viver em zonas rurais, população essa predominantemente constituída de jovens $(61 \%$ abaixo de 24 anos) e com baixíssimo índice de escolaridade e alfabetização.

A mortalidade infantil, em algumas dessas áreas, compara-se à dos países mais atrasados do mundo; com cerca de $50 \%$ dos óbitos ocorrendo antes dos 5 anos de idade e tendo como causa mais freqüente de morte a desnutrição e as enfermidades ligadas à falta de saneamento básico. (Landmann, 1978, pág. 661) .

Tem sido insuficiente o suporte de recursos financeiros, materiais e humanos devido às dotações orçamentárias do Ministério da Saúde. O número médio de unidades de saúde, leitos hospitalares, profissionais de saúde, etc., por população é significativamente pequeno num quadro comparativo de vários países. Na deficiência de profissionais de saúde, nosso país desponta entre os de piores condições na América Latina, no que se refere aos profissionais de niveis médio e elementar. (Theofilo, 1977, pág. 37).

Os recursos humanos na área de saúde apresentam uma estrutura qua- litativa e uma composição profissional que respondem à natureza e às características da prática dominante, que se reforça pela tecnologia sofisticada, aplicada na indústria da saúde, a qual não tem compromisso com a saúde da população.

Segundo Santos (1978, pág. 41), excetuando-se os raríssimos casos individuais, não temos no Brasil o médico geral da família. Do ponto de vista da prática liberal (livre escolha do médico pelo paciente e livre escolha dos métodos de diagnóstico e terapêuticos e dos honorários, pelo médico) não há clientela para os mais de 100.000 médicos que teremos em 1980. Na melhor das hipóteses, há clientela particular para aproximadamente 1.000 médicos gerais, mas esta clientela é justamente a elite social que procura e remunera diretamente a medicina especializada.

Não é surpreendente que o aparelho formador de recursos humanos privilegie a formação das categorias profissionais de mais elevado status e negligencie a formação de "auxiliares". A conseqüência é que estamos bem próximos de uma disponibilidade de médicos e odontólogos igual ou superior aos padrões recomendados e nos mantemos em um crescente déficit de enfermeiros e pessoal de nível médio (Macedo, 1977, pág. 19) .

Para a formação de pessoal, evidencia-se uma preocupação dominante com o ensino e não com a aprendizagem, com as profissões (especialistas) e não com a equipe de saúde, com o domínio da técnica específica e não com a capacidade crítica e criadora frente à realidade. A educação (formação) constitui um instrumento de promoção social individual, mas não está instrumentando propósitos de mudanças em saúde. Ao contrário, está conplicando as práticas vigentes dos recursos humanos que forma.

Por outro lado, a forma assalariada de exercício profissional comporta hoje 
PEDRAZZANI, J.C. - Formação do profissional de saúde. Estrutura ocupacional e demandas educacionais. Rev. Bras. Enf.; DF, 33 : 477-482, 1980.

numerosos constrarigimentos e múltiplos inconvenientes para o sistema de saúde global, incluindo o público, privado e socializado.

A concentração capitalista, acrescida das superespecializações, está impondo, realmente, uma transformação do exercício profissional: substituiçäo do médico artesão ou liberal pelo de equipe e assalariado.

O que vemos hoje, no terreno do exercício profissional (saúde), é a tendência de crescer, sempre e mais, o campo da concentração das atividades, divididas em múltiplas especialidades, como ainda a tendência para o assalariado médico em instituições e empresas, quer privadas, quer estatais ou para-estatais. Enquanto isso, a medicina artesanal e a liberal irão passando, gradualmente, para a página da história. O médico da família, dos tempos medievais, e o clínico, nosso contemporâneo, ambos como profissionais individualistas, só existirão como remanescentes de outras eras, em regiões de interior, onde a moderna técnica ainda não tenha chegado.

Mello (1978, pág. 35) enfatiza que não se pretende extinguir a figura do especialista nos mais variados ramos da medicina. Segundo o autor, o que se deve postular, em última análise, é o aumento do número de profissionais que tenham ampla visão dos problemas de saúde, que tenham conhecimentos gerais da prática médica, que não discriminem os aspectos preventivos dos aspectos curativos do exercício profissional.

Para garantir a formação do médico generalista, bem como de outros profissionais da área da saúde, mesmo que as escolas do país, de modo geral, dispusessem de leitos em número suficiente para o envio, seria necessário que os futuros profissionais tivessem contatos com problemas de saúde que são preferentemente atendidos em outras unidades do sistema.
A importância dessa prática é reconhecida pela comissão de ensino médico do Ministério da Educação e Cultura, quando afirma: "a formação do médico deve ser feita não apenas nos hospitais universitários ou de ensino, senão também em outras unidades do sietema de saúde." (Apud, Mello, 1978, pág. 37) .

Observa-se um déficit na área de recursos para o atendimento do setor saúde no Brasil. As estimativas calculadas para esse setor constam do Plano Decenal de Saúde para as Américas 1971/1980.

Para elaboração de dados que indicam esse déficit, o Plano Decenal tomou como base a população (habitantes $\mathrm{x}$ profissionais). Um outro indicador também utilizado para estabelecer proporções entre os diversos níveis de profissionais toma como base o profissional de maior destaque; no caso do setor saúde, a proporção do número de profissionais é estabelecida segundo o número de médicos.

$\mathrm{Na}$ verdade, o déficit estipulado, segundo os indicadores acima, resulta de uma situação que seria a ideal, mas não a real. Para se conhecer a situação real, há necessidade de desenvolver pesquisas junto ao mercado de trabalho e $\overline{\mathrm{e}}$ tabelecer as proporções empregadas pelas diversas instituições utilizadoras do recursos humanos produzido nos bancos escolares ou nas próprias empresas.

A profissão de enfermagem no Brasil apresenta uma característica "sui generis" entre as profissões da área dá saúde, porque é exercida por pessoal de diferentes níveis de formação, constituindo uma equipe com a conformação de uma pirâmide, tendo como ápice os profissionais de nível superior, responsáveis pelo desenvolvimento da profissão e pela qualidade da assistência prestada pelos outros membros da equipe; no corpo, com formação já regula- 
mentada, encontra-se o pessoal de nivel técnico e auxiliar, executores de grande parte das ações de enfermagem, na assistência direta a indivíduos, família e comunidade, e na base da pirâ- mide, coloca-se a grande maioria constituída por aqueles que exercem ocupações de atendente de enfermagem, não contando ainda com sua formação regulamentada.

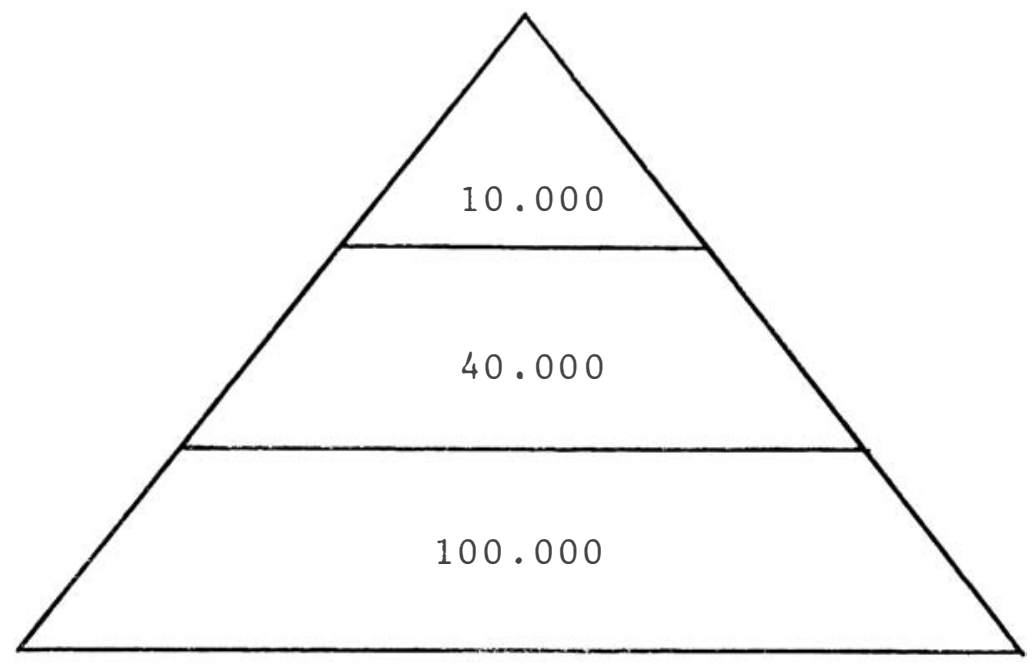

(FIG. 1)

Distribuiçāo numérica dos níveis profissionais de Enfermagem no Brasil (1973)

A figura 1 esboça a hierarquia existente na profissão de enfermagem no Brasil. Os dados indicados são aproximados, pois, em 1973, de acordo com a publicação feita pelo IBGE em 1975, os totais dos vários níveis eram os seguintes: 9.511 enfermeiros, 37.715 auxiliares de enfermagem e 91.606 atendentes de enfermagem (Matos, 1978, pág. 19).

"Essa diversidade é o fato de que a maioria dos que exercem a enfermagem não são devidamente qualificados, têm contribuído para a formação de uma imagem desfavorável da profissão na sociedade, constituindo um dos fatores que dificultam o seu desenvolvimento". (Matos', 1978, pág. 19). Ainda, segundo Matos, um dos fatores mais importantes e que vem contribuindo negativamente, no que refere ao destaque da profissão frente à sociedade, é o fato da Enfermagem ser exercida predomi- nantemente por mulheres, as quais ainda lutam para liberar-se de condicionamentos e limitações impostos pela nossa cultura.

Observa-se certo incremento no percentual de empregos de auxiliares de enfermagem e redução no de atendentes. Entretanto, ocorre um decréscimo no percentual de empregos para enfermeiros, o que é muito desfavorável, uma vez que cabe a esse elemento a liderança da equipe. (Matos, 1978, pág. 16).

Enquanto a preocupação estiver canalizada na substituição do atendente de enfermagem pelo auxiliar de enfermagem, jamais o enfermeiro será reconhecido como tal, pois sua necessidade estará encoberta por um profissional de menor qualidade, cuja diferença de desempenho profissional a população não percebe, ou, se isto acontece, aceita passivamente. Esse quadro de substi- 
PEDRAZZANI, J.C. - Formação do profissional de saúde. Estrutura ocupacional e demandas educacionais. Rev. Bras. Enf.; DF, 33 : 477-482, 1980.

tuiçāo de profissionais da equipe de enfermagem se reforça através dos mecanismos desenvolvidos pelos órgãos empregadores para conter a elevação de suas folhas salariais. O profissional auxiliar é menos honeroso e daí uma das razões de observar-se um reduzido número de enfermeiros nas equipes de saúde. As empresas da saúde visam o lucro imediato e aparente e não os prejudicados; sendo a doença a mercadoria de lucro destas empresas, por que melhorar o nível da saúde da população?

Prevenir e higienizar, eis o supremo objetivo da medicina como ciência; para ele convergem e culminam todos os seus conhecimentos; e é nele, ainda, que a humanidade deposita suas maiores esperanças. Esse objetivo não pode ser senão obra do Estado e os seus agentes, outra coisa não podem ser senão funcionários públicos. (Faria, 1978, págs. 2529) .

Sem buscar outras fontes, numéricas, que esclarecessem mais a nossa posição, citaremos, como exemplo, o maior empregador de pessoal de Enfermagem no país (INAMPS), o qual é um órgão de previdência social, sem fins lucrativos, que opera com proporções, entre as categorias profissionais que, teoricamente, aproximam-se do ideal. Seu quadro é constituído de 3.283 enfermeiros; 11.554 auxiliares de enfermagem e 25.685 atendentes (auxiliares operacionais de serviços) .

Seguindo a linha de nossa proposição: elevar o nível de saúde da população através de profissionais mais qualificados e mais críticos, deparamo-nos com uma pano de fundo ainda pouco discutido na Enfermagem.

Constata-se a contradição da linguagem, pois se prega maior e melhor qualidade e quem executa e decide é o menos qualificado.

Outra contradição é a que se estabelece nos níveis intermediários da pro- fissão, pois, quais as diferenças dos currículos entre auxiliares e técnicos de enfermagem e as funções na prática destas categorias?

Com isso, não queremos afirmar que a enfermagem é a única responsável pela transformação no setor saúde, mas uma parcela é de sua responsabilidade. O que nos parece é a falta de assumir esta parcela com mais consciência crítica, sobre a situação concreta de doença da população.

Reconhecendo que o enfermeiro é o profissional mais qualificado para a prestação de serviços dentro da equipe de enfermagem, questiona-se o fato de não ser este profissional também em maior número. Se a essa maior quantidade implica em melhor qualidade, é a comunidade necessitada quem se beneficiará de uma inversão nas proporções existentes na equipe de enfermagem.

Desta forma a sociedade passará a reconhecer e identificar o profissional de enfermagem, e o ensino universitário estará cumprindo com partes de seu dever nesta área, frente à comunidade.

\section{CONCLUSÃO}

O nível de saúde da população brasileira agrava-se proporcionalmente ao tipo de serviço prestado neste setor. Apontamos como principal responsável pelo problema a estrutura social de poder que mantém o controle do processo formador de profissionais de saúde.

Controle que pode ser verificado através do interesse por maior número de especialistas dentro das diversas profissões, pela ênfase na tecnologia curativa; tendo como consequiência a realização do trabalho efetivo por pessoal de baixo qualificação, a fim de proporcionar maior lucro às empresas dominadas pelo poder controlador.

Enquanto não nos conscientizarmos da necessidade da definição de nosso 
PEDRAZZANI, J.C. - Formação do profissional de saúde. Estrutura ocupacional e demandas educacionais. Rev. Bras. Enf.; DF, 33 : 477-482, 1980.

papel na interação com a equipe de saúde, cumprindo e fazer com que os outros profissionais cumpram com suas partes, no que tange ao atendimento da saúde da população e não aos interesses lucrativos que visam principalmente à doença. Estaremos contribuindo com um programa de saúde postulado em um projeto teórico, o atu (Sistema Nacional de Saúde), que é pouco viável na prática e ao mesmo tempo reforçando-o em detrimento das necessidades da população.

E, em vista da impossibilidade de nós, enfermeiros, atuarmos a nível de super-estrutura para interferirmos decisivamente no sistema de saúde vigente e os que lá estão, parecem-nos ter demonstrado muito pouco interesse pela saúde da população, resta-nos algumas recomendações:

- Seguindo nossa abordagem, talvez na sua aparência simples, detecta-se que o ensino de maneira geral, e aqui espe- cificamente o de enfermagem, está desvinculado daquilo que o profissional formado deveria exercer na prática, julgamos que seria uma questão a ser discutida e ajustada por todos aqueles que se interessam pela saúde da população;

- E que, as escolas de Enfermagem, em particular, tivessem como orientação básica de ensino a formação de profissionais críticos e capazes de proporem soluções objetivas no setor de sua competência;

- Que nós, enfermeiros, nos organizemos através de nossas entidades de classe, a fim de analisar todas as possíveis variáveis que interferem na formação e utilização dos profissionais de saúde e, em especial, de enfermagem, para que possamos validar alguma(s) proposta(s) de mudança(s) no papel da Enfermagem frente às necessidades cle saúde da população.

\section{BIBLIOGRAFIA}

BASTOS, N. C. de B. - A Educação Contínua nas Profissões de Saúde. Revista da Fundação SESP. 33(2) : 31-37, São Paulo, 1978.

FARIA, A. - Socialização da Medicina. Saúde em Debate. 7/8: 25-29, abr.-mai.jun. 1978.

LANDMANN, J. - Saúde e Assistência Médica: Determinantes. $R B M$ 35(11): 653668, nov. 1978.

LESER, W. - Relacionamento de certas características populacionais com a mortalidade infantil no município de São Paulo, de 1950 a 1970. Secretaria do Estado de São Paulo. 1(6): 4-5, março, 1977.

MACEDO, C. G. de - Recursos Humanos para a Saúde. Documento Básico para Temas Oficiais do XIX Congresso Brasileiro de Higiene. São Paulo, outubro 1977.

MATOS, A. V. - A Enfermagem e o Sistema Nacional de Saúde in: Anais do $X X X$ Congresso Brasileiro de Enfermagem. ABEn, 1978, págs. 13-50.
MELLO, C. G. de - A formação do Médico Generalista e a Medicina Preventiva. Saúde em Debate. 7/8:30-38, abrilmaio-junho 1978.

MOHIS, J. F. R. de - Construção Social da Enfermidade. Cortez \& Moraes. São Paulo, 1978.

RODRIGUES, B. A. - Aspectos da Evolução da Saúde Pública no Brasil. Revista da Fundação SESP. 33(2): 10-19. São Paulo, 1978.

SANTOS, N. R. dos - Contribuição ao Atendimento do Novo Médico Geral ou de Família. Saúde em Debate. 7/8: 3943, abril-maio-junho 1978.

SINGER, P. e outros - Prevenir e Curar. Rio de Janeiro. Forense - Universitária, 1978.

THEOPHILO, F. V. - Problemática dos Serviços de Saúde Urbanos e Rurais. Documentos Básicos para discussão dos Temas Oficiais do XIX Congresso Brasileiro de Higiene. Págs. 28-50. São Paulo, 1977. 